\title{
Synthesis of cyclic carbonates from epoxides and carbon dioxide catalyzed by talc and other phyllosilicates
}

\author{
Fiona Nakibuule ${ }^{1,2}$, Steven Allan Nyanzi ${ }^{1}$, Igor Oshchapovsky ${ }^{2,3}$, Ola F. Wendt ${ }^{2}$ and Emmanuel Tebandeke ${ }^{1 *}$ (i)
}

\begin{abstract}
Naturally occurring phyllosilicate minerals such as talc and vermiculite in conjunction with n-tetra butyl ammonium bromide (TBAB) co-catalyst were found to be efficient in the coupling of $\mathrm{CO}_{2}$ with epoxides to form cyclic carbonates. The reaction was carried out in a pressurized autoclave reactor at moderate pressures of 10-35 bars and temperatures of $100-150^{\circ} \mathrm{C}$. The optimized catalyst system exhibited $>90 \%$ conversion of the epoxides and $>90 \%$ selectivity for the desired cyclic carbonates, in the presence or absence of a solvent. The selectivity of the catalytic system could be improved with heat pre-treatment of the phyllosilicates albeit this resulted in slightly lower epoxide conversion. The results obtained using the heat treated phyllosilicates strongly support the hydrogen bond assisted mechanism for the cycloaddition of epoxides and $\mathrm{CO}_{2}$. The cycloaddition reaction could also be carried out in the absence of TBAB, although lower cyclic carbonate yields were observed. The phyllosilicate part of the catalyst system is heterogeneous, easy to separate after completion of reactions and reusable a number of runs without loss of activity.
\end{abstract}

Keywords: Carbon dioxide, Cycloaddition, Cyclic carbonates, Epoxides, Talc, Phyllosilicates

\section{Introduction}

Modern societies today are highly dependent on carbonaceous fossil fuels as the primary source of energy [13]. Complete combustion of these fuels produces carbon dioxide $\left(\mathrm{CO}_{2}\right)$, a gas whose concentration in the atmosphere has increased significantly: and is believed to contribute significantly to global warming $[4,5]$. There are increasing concerns for global warming and heightened interest worldwide to reduce $\mathrm{CO}_{2}$ atmospheric emissions. One of the solutions being considered to this problem is converting $\mathrm{CO}_{2}$ into chemical products for which there is significant commercial demand [6-8]. Although the amount of $\mathrm{CO}_{2}$ that can be consumed through chemical production is small compared to the amount

\footnotetext{
*Correspondence: emmanuel@cns.mak.ac.ug

${ }^{1}$ Department of Chemistry, College of Natural Sciences, Makerere

University, P. O. Box 7062, Kampala, Uganda

Full list of author information is available at the end of the article
}

generated by fossil fuel combustion, its conversion nevertheless would be favorable from the green chemistry perspective. Moreover, if done efficiently, using $\mathrm{CO}_{2}$ as a chemical feedstock, would constitute a net positive contribution towards sustainability [9-11]. Unfortunately, due to the thermodynamic stability of $\mathrm{CO}_{2}$ its activation and insertion into organic molecules still remains a challenge. A promising process in $\mathrm{CO}_{2}$ chemical fixation, is its insertion into epoxides to produce cyclic carbonates (Scheme 1).

The $\mathrm{CO}_{2}$ and epoxide cycloaddition reaction, proceeds with $100 \%$ atom economy, and thus constitutes one of the most efficient examples of artificial $\mathrm{CO}_{2}$ fixation. Moreover, this approach of cyclic carbonate production is environmentally benign compared to the traditional syntheses, which involve use of the highly toxic and corrosive phosgene [12]. Cyclic carbonates have found extensive use as excellent aprotic polar solvents, electrolytes in secondary batteries, monomers in the production 


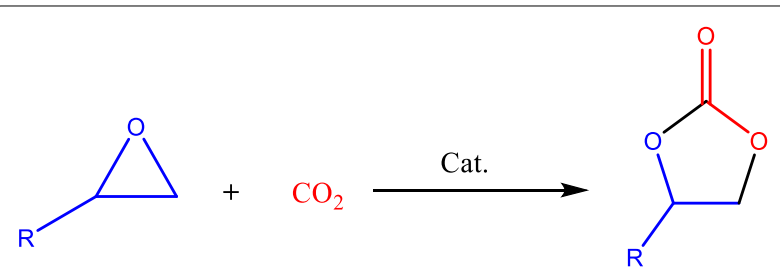

Scheme 1 Cyclic carbonate synthesis

of polycarbonates, chemical ingredients in preparation of medicines or agricultural chemicals, and other applications [13-15].

Several industrial processes for cyclic carbonate production from $\mathrm{CO}_{2}$ employing homogeneous catalysts have been reported [15-17]. Although a number of these catalytic systems exhibit high efficiency, the catalysts are undesirably dissolved in the phase containing the cyclic carbonates, creating separation and purification challenges at the end of the process. In contrast, inorganic heterogeneous catalysts tested in the cycloaddition process offer some advantages such as ease of post reaction separation, recyclability and high thermal stability. Indeed, various inorganic heterogeneous catalysts, such as $\mathrm{Mg}-\mathrm{Al}$ mixed oxides [18], basic metal oxides [19-21], iron-based composite [22], smectites [23, 24], and zeolites $[25,26]$, have been reported for this process. Unfortunately, several of these solid catalysts have insufficient activity and most of them require additives to ensure reasonable conversion and selectivity. Thus, research in the development of low cost, thermally stable and efficient heterogeneous catalysts for coupling of $\mathrm{CO}_{2}$ and epoxides, is still gaining considerable interest. Taking into account that some silicate-based catalysts like zeolites $[25,26]$ and smectites $[23,24]$ have demonstrated promising catalytic activity in the $\mathrm{CO}_{2}$ and epoxide cycloaddition reaction under mild conditions, further testing and exploration of this group of minerals is highly desirable. These materials have advantages including: natural occurrence, low cost, their synthetic analogues are easy to prepare; and the catalyzed reaction proceeds in heterogeneous phase, hence offering easy catalyst separation and recyclability $[25,26]$.

The smectites belong to the phyllosilicate group of silicates, which includes minerals such as talc, vermiculite, biotite, phlogopite, among others [27]. Most of the minerals in this group are layered and are comprised of octahedral and tetrahedral sheets. The octahedral sheets contain divalent or trivalent cations such as $\mathrm{Mg}^{2+}$ and $\mathrm{Al}^{3+}$ surrounded by six oxygen atoms, whereas the tetrahedral sheets contain $\mathrm{Si}^{4+}$ cations surrounded by four oxygen atoms. Generally, most of the phyllosilicates are $\mathrm{OH}$ bearing in their structures and contain varying amounts of other metal cations. The presence of numerous hydroxyl groups and active metal cations such as $\mathrm{Mg}^{2+}, \mathrm{Al}^{3+}, \mathrm{Fe}^{2+}$ in the structures of the phyllosilicates strongly suggests that they have catalytic potential in the cycloaddition reaction; particularly considering the hydrogen bond assisted mechanism of $\mathrm{CO}_{2}$ and epoxide coupling [22]. A number of studies have indicated that hydrogen bonding between the catalyst and substrate plays a key role in enhancing reactions [28]. Indeed, catalytic materials rich in hydroxyl groups have proved to be efficient hydrogen bonding catalysts [29-31]. Qu and co-workers [22], reported that hydrogen bonding at the solid/liquid interface can activate epoxides and stabilize ring opening intermediates. It has also been reported that through hydrogen bonding, small amounts of water can assist a Lewis base catalyzed reaction between an epoxide and $\mathrm{CO}_{2}$ [32]. Further on, studies have shown that the weakly acidic surface silanol groups can activate propylene oxide, which subsequently reacts with a nucleophile to open the epoxide ring [33]. A combination of the previous observations motivated this investigation into the performance of phyllosilicate minerals as catalysts for cyclic carbonate synthesis.

Herein we report an efficient catalytic system for the phosgene-free conversion of $\mathrm{CO}_{2}$ into cyclic carbonates catalyzed by talc, vermiculite and other phyllosilicates, in conjunction with tetra butyl ammonium bromide (TBAB). The $\mathrm{CO}_{2}$ and epoxide coupling process was carried out without addition of TBAB co-catalyst in some experiments, albeit with lower yields of cyclic carbonates. The phyllosilicates contain several hydroxyl groups to facilitate the coupling of $\mathrm{CO}_{2}$ and epoxides, and the results of this study, strongly support the hydrogen bond assisted mechanism of the cycloaddition process. The phyllosilicates used in this study are naturally occurring, and some of them were sampled from deposits in Uganda. The low cost and natural abundancy of silicate and alumina minerals, coupled with their unique properties make them valuable in several catalytic applications [34].

\section{Results and discussion}

\section{Elemental composition of talc and vermiculite}

The elemental composition data for talc used in this study is presented in Table 1 . The results show presence of significant amounts of $\mathrm{Si}, \mathrm{Mg}, \mathrm{Al}$ and $\mathrm{Fe}$, whereas other elements such as $\mathrm{Ca}, \mathrm{K}, \mathrm{Na}, \mathrm{Mn}$ and $\mathrm{Cr}$ were detected in low amounts. These compositions are consistent with the reported structure of talc [27]. Talc is mainly comprised of $\mathrm{Mg}$ in the octahedral sheet and Si in the tetrahedral sheets; the presence of other elements such as $\mathrm{Al}$ and Fe suggests tetrahedral or octahedral substitutions, for example $\mathrm{Fe}$ normally substitutes for $\mathrm{Mg}$ in the octahedral layer [35]. 
Table 1 Elemental composition of talc and vermiculite

\begin{tabular}{llcl}
\hline Entry & $\begin{array}{l}\text { Element } \\
\text { expressed } \\
\text { as oxide }\end{array}$ & $\begin{array}{l}\text { Talc composition } \\
\text { [wt.\%] }\end{array}$ & $\begin{array}{l}\text { Vermiculite } \\
\text { composition } \\
\text { [wt.\%] }\end{array}$ \\
\hline 1 & $\mathrm{SiO}_{2}$ & 54.28 & 42.98 \\
2 & $\mathrm{Al}_{2} \mathrm{O}_{3}$ & 2.48 & 14.24 \\
3 & $\mathrm{Fe}_{2} \mathrm{O}_{3}$ & 6.07 & 7.13 \\
4 & $\mathrm{MgO}$ & 29.35 & 21.35 \\
5 & $\mathrm{CaO}$ & 1.22 & 2.06 \\
6 & $\mathrm{MnO}$ & 0.26 & 0.18 \\
7 & $\mathrm{~K}_{2} \mathrm{O}$ & 0.12 & 0.92 \\
8 & $\mathrm{Na}_{2} \mathrm{O}$ & 0.25 & 0.48 \\
9 & $\mathrm{Cr}_{2} \mathrm{O}_{3}$ & 0.08 & 0.04 \\
Sum* & & 94.1 & 89.4 \\
\hline
\end{tabular}

*Sum excluding volatiles such as water.

The observed chemical composition of talc is comparable to that reported for naturally occurring talc deposits from Lamal Pougue, Cameroon [36]. However, it should be noted that every talc deposit is unique with regard to chemistry and morphology due to variations in geological formation [27]. The elemental composition data for the vermiculite sample used in the study presented in Table 1 , show significant amounts of $\mathrm{Si}, \mathrm{Mg}, \mathrm{Al}, \mathrm{Fe}$ and $\mathrm{Ca}$; other elements such as $\mathrm{K}, \mathrm{Na}, \mathrm{Mn}$ and $\mathrm{Cr}$ were also detected in low amounts. These observations are consistent with the structure of vermiculite [27], and is comparable with the reported chemical composition of naturally occurring deposits $[37,38]$.

\section{Infrared spectroscopy of the talc catalyst}

The IR spectrum of the talc material is shown in Additional file 1: Figure S1. The spectrum shows peaks at 451 and $469 \mathrm{~cm}^{-1}$ which are attributed to $\mathrm{Mg}-\mathrm{O}-\mathrm{Si}$ and $\mathrm{Si}-\mathrm{O}-\mathrm{Si}$ bending vibrations, respectively. The sharp absorption at $669 \mathrm{~cm}^{-1}$ is attributed to the bending vibration of $\mathrm{Mg}-\mathrm{OH}$ in the talc structure. The absorption band at $1014 \mathrm{~cm}^{-1}$ is due to stretching vibration of $\mathrm{Si}-\mathrm{O}$ of the $\left[\mathrm{SiO}_{4}\right]$ tetrahedra $[39,40]$. However, the observed intensities of some bands were relatively weak compared to those reported in previous studies [35, 41, 42]. This could be attributed to structural degradation of the octahedral and tetrahedral sheets under mechanical stress of grinding, and possibly lower content of $\mathrm{OH}$ groups in the pristine mineral. Some bonds in the talc structure such as $\mathrm{Mg}-\mathrm{O}$ and $\mathrm{Mg}-\mathrm{OH}$ may break during grinding, resulting in disruption of linkages between octahedral and tetrahedral sheets [41].

\section{BET studies of the talc catalyst}

The BET specific surface area $\left(\mathrm{S}_{\mathrm{BET}}\right)$ for the talc catalyst was $2.78 \mathrm{~m}^{2} / \mathrm{g}$, with a pore size of $296.7 \AA$ and a mesoporous pore volume of $0.02 \mathrm{~cm}^{3} / \mathrm{g}$. The microporous pore volume was negligible $\left(\leq 0.0003 \mathrm{~cm}^{3} / \mathrm{g}\right)$. The $\mathrm{N}_{2}$ adsorption-desorption isotherm of the talc catalyst as shown in Additional file 1: Figure S2 is characterized by a Type IV isotherm with a narrow hysteresis that spreads across part of the plateau region of the adsorption curve, characteristic of materials with slit-shaped pores [43]. The isotherm obtained for talc in this study, is similar to those reported for talc and other mesoporous materials by Sprynskyy and co-workers [44].

\section{Powder X-ray diffraction of talc}

The powder X-ray diffraction pattern of the talc catalyst is shown in Fig. 1. The relative intensity and peak positions of the XRD pattern are in agreement with the typical structure of talc. The XRD data show the $2 \theta$ and crystal plane (hkl) values of three important peaks of talc including $2 \theta_{001}=9.40^{\circ}, 2 \theta_{002}=19.90^{\circ}$, and $2 \theta_{003}=28.90^{\circ}$. The XRD peaks are similar to the ones reported for the E-4 Emirdağ samples (actinolite $5 \%$ and talc $95 \%$ ) by Ersoy and co-workers [42], but without the actinolite peak $\left(2 \theta=10.90^{\circ}\right)$. A comparison of the experimental pattern, with the theoretically calculated one from the fully ordered model according to Perdikatsis and Burzlaff [45], also shows similarities in the structure albeit a few discrepancies, such as absence of some peaks between $20^{\circ}$ and $35^{\circ}$ due to structural disorder. The obtained data is also in agreement with the results reported by Kumar and co-workers [46] for milled talc samples. In general, positions of the strongest peaks coincide, but there are some absent peaks and shoulders near existing peaks. The shape of the peaks between $15^{\circ}$ and $40^{\circ}$ could be attributed to structure distortion usually caused by conditions of growth and/or metamorphization of the mineral. In addition, the distortion can be due to effects of grinding that could cause progressive structural disorder and subsequent amorphization of crystallites [41]. It is also common that during intensive grinding, the XRD basal 001 peak of talc decreases in intensity, whereas the 002 peak may disappear completely and an increase in background in the $2 \theta=15^{\circ}-40^{\circ}$ due to the formation of amorphous material is also expected [41]. Another important observation made is the similarity of the XRD pattern to the one obtained by Kogure and co-workers [47] in which the authors suggested that such a pattern is typical for silicates with extensive stacking disorder. Moreover, the peaks, absent on the experimental XRD pattern but existing on the theoretical pattern of the fully ordered model [45], further suggests stacking faults in the talc sample, 


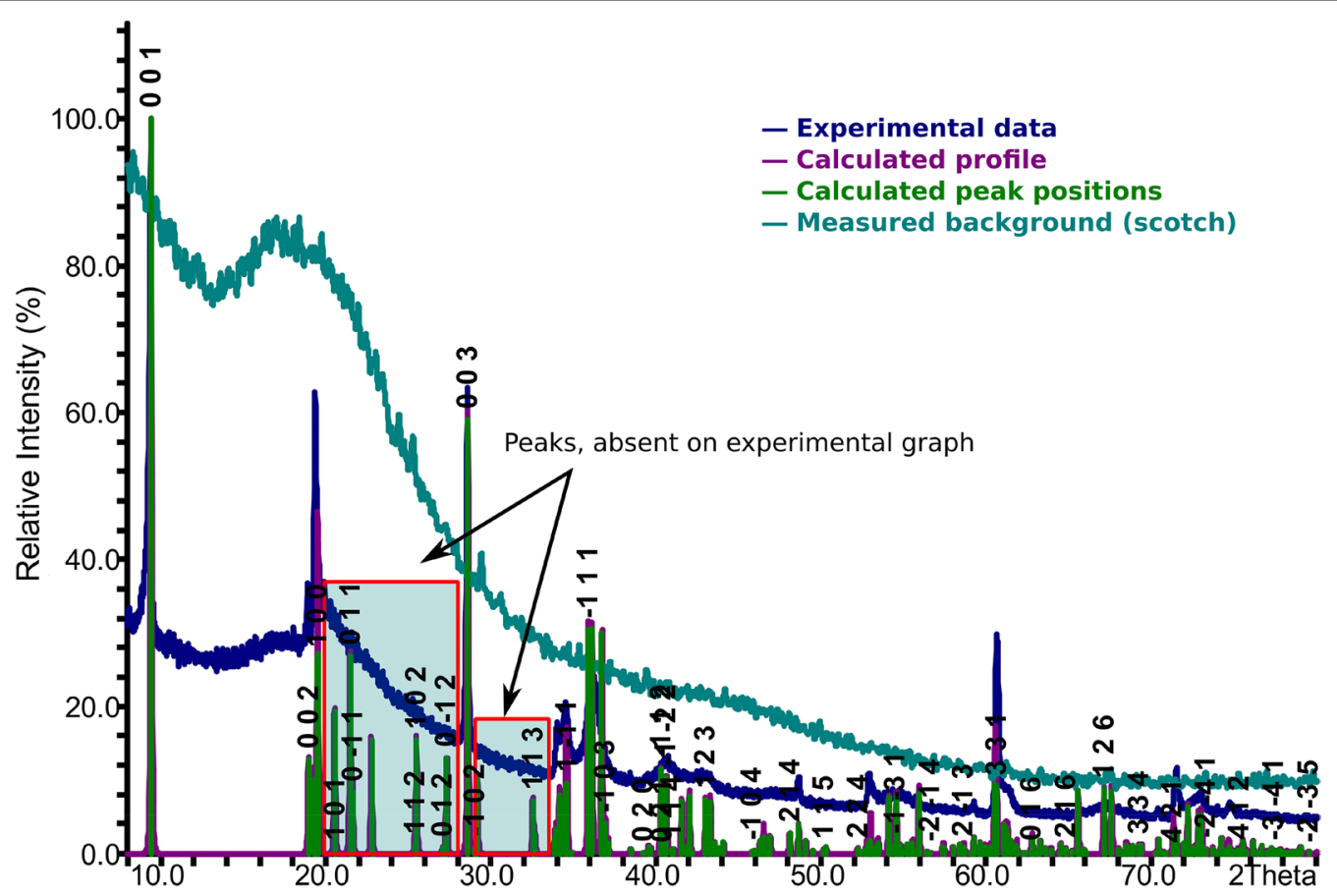

Fig. 1 The experimental powder XRD pattern for talc and the calculated pattern from the completely ordered structure model [45]

as the same peaks are also absent in powder patterns of pristine talc samples in previous studies [41, 42, 47].

The elemental composition, IR spectroscopy and powder X-ray diffraction results obtained for talc in this study, are all consistent with the reported structure [27]. The structure of talc $\mathrm{Mg}_{3}(\mathrm{OH})_{2} \mathrm{Si}_{4} \mathrm{O}_{10}$ consists of alternating layers of vertex-sharing $\left[\mathrm{SiO}_{4}\right]$ tetrahedra and corner-sharing $\left[\mathrm{MgO}_{6}\right]$ octahedra. Two tetrahedral layers sandwich one octahedral layer through shared oxygen atoms, to form a 2:1 tri-layer, as shown in Fig. 2 which was generated using crystallographic data from Perdikatsis and Burzlaff [45]. These tri-layers are weakly connected to each other (Fig. 2a); which explains why inter- and intra-layer stacking faults and formation of different polytypes are possible. The $\left[\mathrm{SiO}_{4}\right]$ tetrahedra in the undisturbed talc structure form hexagonal rings (Fig. 2b) around the hydroxyl groups that are attached to the $\left[\mathrm{MgO}_{6}\right]$ octahedra as magnesol $(-\mathrm{Mg}-\mathrm{OH})$ groups. These sites are favourable for adsorption since a high coordination number of the adsorbed reactant is possible. The adsorbate can form up to 6 bonds to oxygen atoms: 6 bonds to silicon atoms and one hydrogen bond to the hydrogen from the hydroxyl group. The approximate radius of such adsorption site is $1.125 \AA$, taking into account the largest distance between oxygen atoms and their van der Waals radii. But the adsorbate does not need to go inside the hexagonal rings and can stay on top. There are two shortest characteristic distances between such an adsorption sites on the layer: 5.3 and $9.2 \AA$ (Fig. 2b), but they do not match any characteristic distances in the epoxide and $\mathrm{CO}_{2}$. This implies that reactants will be adsorbed more likely only on the highcoordination site, but formation of bonds with other lowcoordination sites is also possible.

In other words, the outer surface of layers could be considered as the most probable sites for catalysis. Other potential catalytic sites such as steps, defects, edges of layers and the region between two truncated hexagonal rings on the edge of crystal (Fig. 2a) could also be active due to the availability of several functional groups. Moreover, when the talc layers are disturbed during grinding, a diversity of functional groups are exposed. Since these were in the interior of the crystal, the valencies of these new functional groups are not completely saturated potentially causing them to be very reactive (vide infra) [48].

\section{Powder X-ray diffraction of vermiculite}

The powder XRD pattern for the vermiculite sample is shown in Fig. 3; generally, the relative intensity and peak positions of the XRD pattern are in agreement with reported structures of vermiculite [37, 38, 49]. The pattern exhibited three small unindexed peaks at $28.4^{\circ}, 43.96^{\circ}$ and $64.7^{\circ}$, which possibly belong to traces of other minerals present in the sample. Among the conventional crystal structure models, 


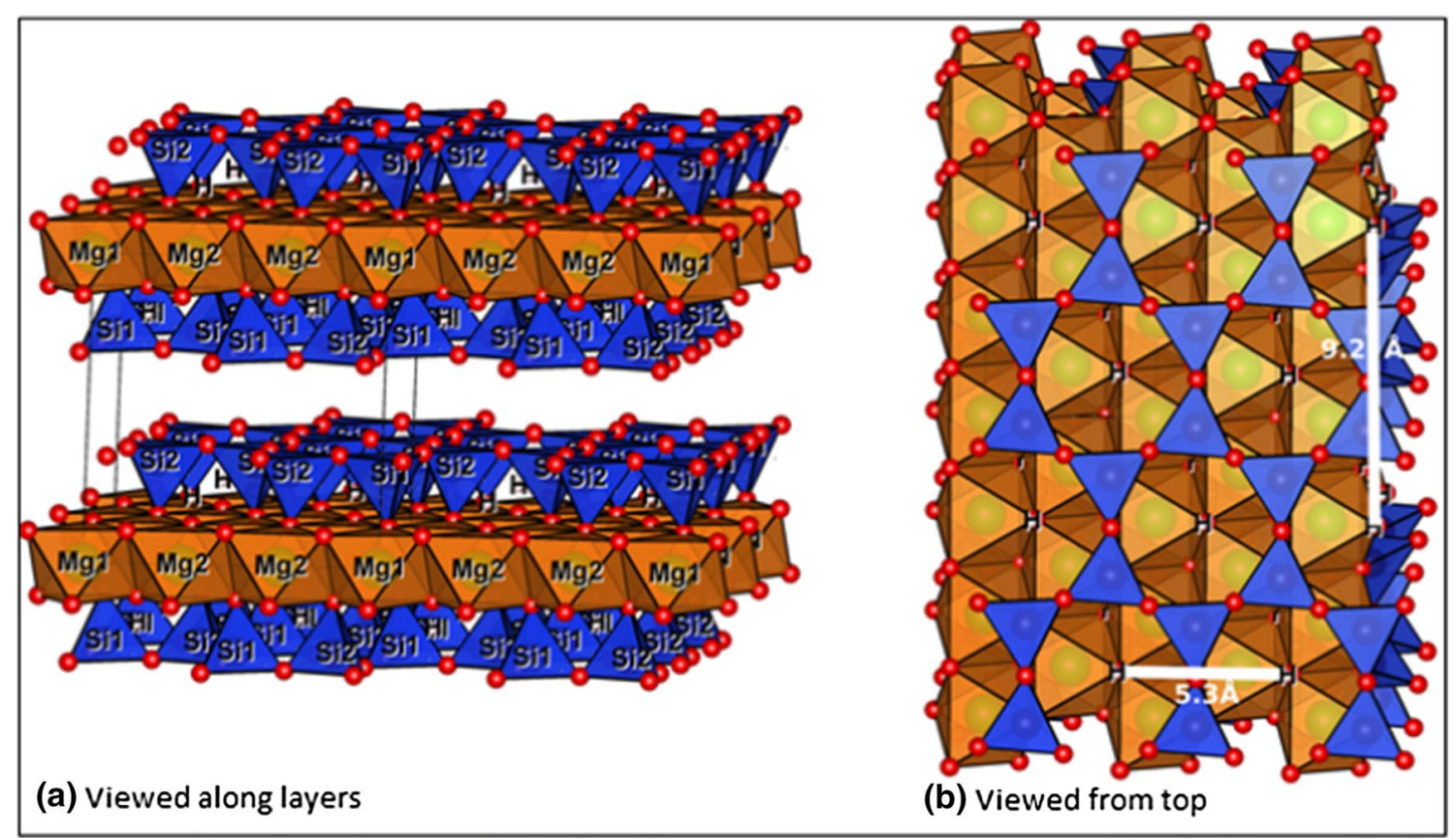

Fig. 2 Simplified structure of talc showing the 2:1 layers generated using crystallographic data taken from Perdikatsis and Burzlaff [45]

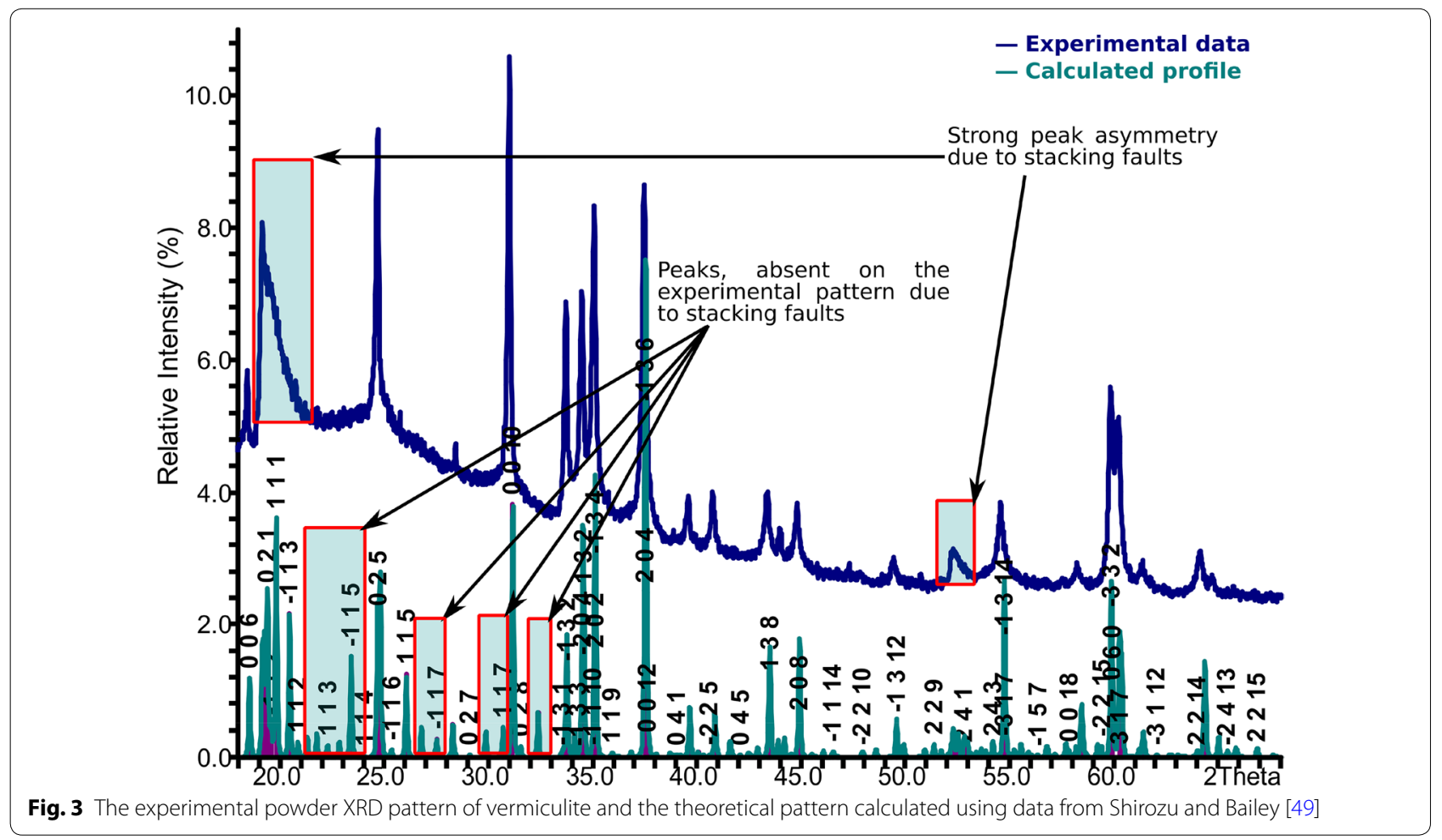

which satisfactorily describe the observed experimental pattern, the model by Shirozu and Bailey [49] is the closest one. A comparison of the XRD pattern with those from previous studies show that the sample has a structure with stacking faults as observed for a vermiculite from Santa Olalla, Spain [37]. However, the 
absence of some reflections together with the strong asymmetry of the peak near $20^{\circ}$ cannot exclude possible grinding effects which may cause progressive structural disorder.

As shown in Fig. 4, which was generated using crystallographic data from Argüelles and co-workers [37], vermiculite consists of talc-like silicate layers along the $a-b$ plane, intercalated by hydrated magnesium ions. The solvated $\mathrm{Mg}^{2+}$ ions with an octahedral coordination of water molecules, are located between bases of $\left[\mathrm{SiO}_{4}\right]$ tetrahedra from adjacent talc-type layers. Minerals with this kind of structure have weaker bonds between layers, which leads to the formation of different polytypes with the same motif, but slightly different relative positions of layers. The common feature of all these structures is the shortest distance between two identical layers, which is equal to $\sim 14.3-15 \AA$. The layers shift relative to each other in a random way in directions $(-a / 3,+b / 3,1)$ or $(-a / 3,-b / 3,1)$. Furthermore, changes in chemical composition and humidity may lead to transformation of one structure into another [38]. The observations about the vermiculite structure suggest that this mineral, like talc, also has catalytic potential in the $\mathrm{CO}_{2}$ and epoxide cycloaddition reaction due to the presence of a number of active sites such as the - $\mathrm{Mg}-\mathrm{OH}$ groups.

\section{$\mathrm{CO}_{2}$ and epoxide cycloaddition reaction}

Initially, the activity of different phyllosilicates in the $\mathrm{CO}_{2}$ and epoxide cycloaddition reaction was tested in the absence of a co-catalyst, using propylene oxide (PO) as a model substrate. The results of the initial screening are presented in Table 2, and show no propylene carbonate (PC) formation for most of the catalysts, with the exception of talc and vermiculite, which produced PC in low yields. When the reaction was repeated under the same conditions but in the presence of a small amount of tetra-n-butylammonium bromide (TBAB) as a cocatalyst, an increase in activity for all catalysts in the coupling of $\mathrm{CO}_{2}$ with $\mathrm{PO}$ was observed. Under these experimental conditions, talc/ $\mathrm{TBAB}$ and vermiculite/ TBAB catalytic systems gave PO conversion of $68.7 \%$ and $60.3 \%$, respectively. This suggested the necessity of a cocatalyst to facilitate the $\mathrm{CO}_{2}$ and epoxide cycloaddition process. Presence of an active solid support sometimes enhances the efficiency of a catalyst system through synergistic action, and absence of which may compromise catalytic performance [50]. The occurrence of synergistic effect in bifunctional catalyst systems consisting of inorganic metal oxides and Lewis bases has been previously observed for the cycloaddition process. Thus, for example, Whiteoak and co-workers [51], improved the cyclic carbonate yield from 0 to $\geq 75 \%$ when they used their catalyst in combination with quaternary ammonium halides.

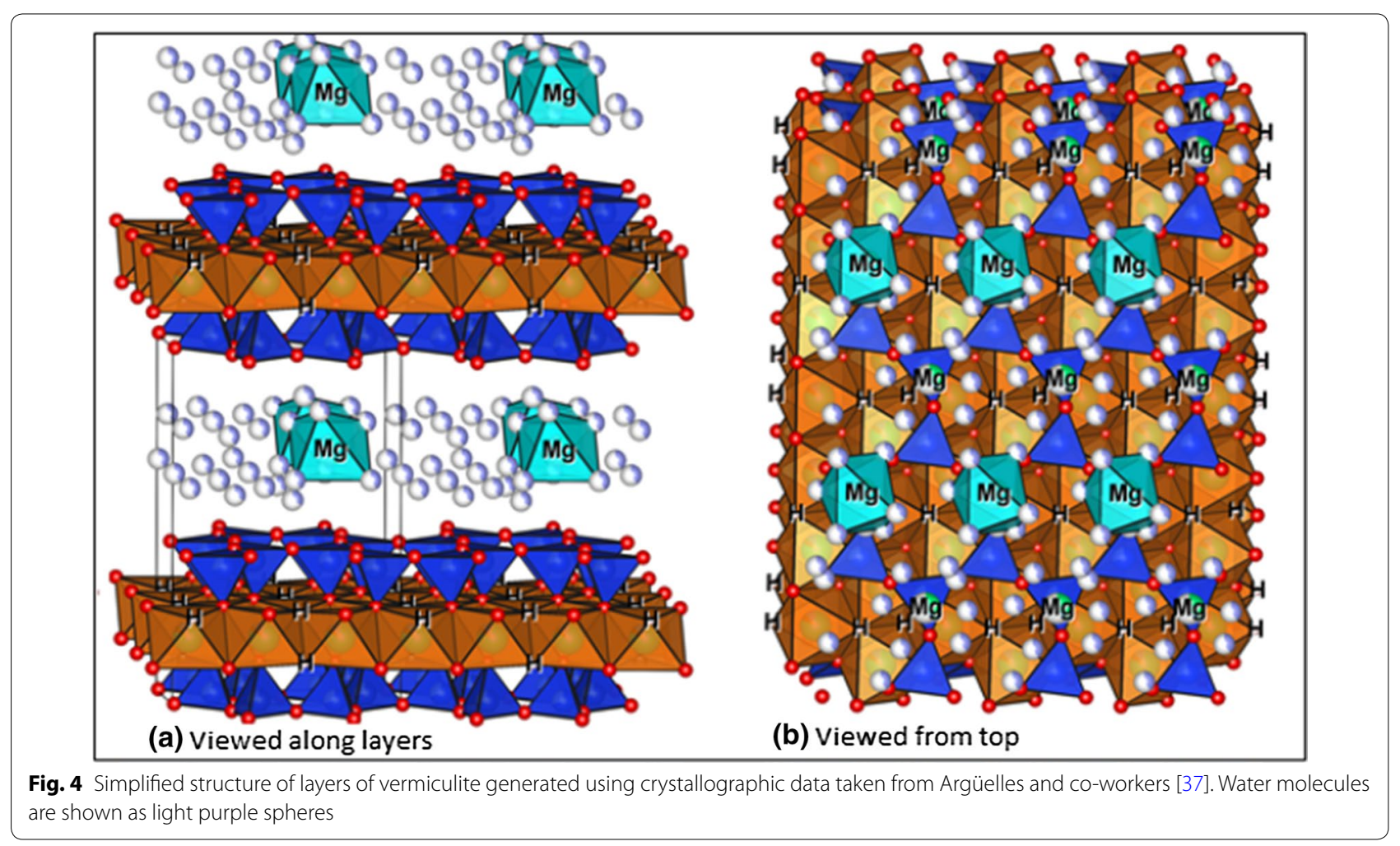


Table 2 Conversion and selectivity in the coupling of propylene oxide (PO) and $\mathrm{CO}_{2}$ to produce propylene carbonate (PC) catalysed by various phyllosilicates at $120^{\circ} \mathrm{C}$

\begin{tabular}{|c|c|c|c|c|}
\hline Entry & Catalyst & Co-catalyst & $\begin{array}{l}\text { PO } \\
\text { Conversion } \\
{[\%]}\end{array}$ & $\begin{array}{l}\text { PC } \\
\text { Selectivity } \\
{[\%]}\end{array}$ \\
\hline
\end{tabular}

\begin{tabular}{lllll}
\hline $1^{\mathrm{a}}$ & Biotite & - & Trace & - \\
$2^{\mathrm{a}}$ & Chlorite & - & 4.3 & - \\
$3^{\mathrm{a}}$ & Phlogopite & - & 3.7 & - \\
$4^{\mathrm{a}}$ & Talc & - & 10.2 & 27.5 \\
$5^{\mathrm{a}}$ & Vermiculite & - & 8.6 & 30.1 \\
6 & Biotite & TBAB & 44.5 & 68.3 \\
7 & Chlorite & TBAB & 55.0 & 70.4 \\
8 & Phlogopite & TBAB & 48.6 & 72.0 \\
9 & Talc & TBAB & 68.7 & 94.2 \\
10 & Vermiculite & TBAB & 60.3 & 96.1 \\
11 & Talc & TBAl & 65.4 & 93.6 \\
12 & Talc & DMAP & 36.9 & 84.7 \\
$13^{\mathrm{b}}$ & - & TBAB & 42.0 & 96.8 \\
\hline
\end{tabular}

Reaction conditions: propylene oxide $(10 \mathrm{mmol})$, catalyst $(100 \mathrm{mg})$, co-catalyst ( $2.5 \mathrm{~mol} \%$ of epoxide), $\mathrm{CO}_{2}$ (20 bars), $\mathrm{CH}_{3} \mathrm{CN}(5 \mathrm{ml})$, Time ( $20 \mathrm{~h}$ )

a No co-catalyst

${ }^{b}$ No phyllosilicate

Also, Wang and co-workers [52], enhanced the performance of 3-hydroxypyridine catalyst from 6 to $\geq 82 \%$ in the presence of tetrabutylammonium iodide (TBAI) as co-catalyst.

However, it should be noted that in this study, only small amounts of TBAB ( $2.5 \mathrm{~mol} \%$ of the epoxide) was used, unlike in previous studies where a slightly higher catalyst loadings and/or higher reaction temperatures of $150^{\circ} \mathrm{C}$ and pressures of 80 bars were utilized [24, 53, 54]. When TBAB was used as the only catalyst, the results were inferior (Table 2, entry 13) to those where both the phyllosilicate and co-catalyst were present, again indicating synergistic roles in the catalytic process. Nevertheless, it should be mentioned that quarternary ammonium salts (QAS) have been employed as sole catalysts in some homogeneous $\mathrm{CO}_{2}$ and epoxide coupling processes, although a high amount of the QAS was employed to achieve significant cyclic carbonate yields. For example, Caló and co-workers [55], used molten tetrabutylammonium halides as solvents and catalysts for the coupling of $\mathrm{CO}_{2}$ with various epoxides and reported yields in the range $10-90 \%$ under optimized reaction conditions.

Results of the initial screening also showed, that the performance of TBAB as a co-catalyst was slightly better than that of TBAI, an observation previously noted when utilizing similar catalytic systems [54]. On the other hand, when $\mathrm{N}, \mathrm{N}$-dimethylamino pyridine (DMAP)
Table 3 Conversion and selectivity in the coupling of PO and $\mathrm{CO}_{2}$ to produce $\mathrm{PC}$ catalysed by talc and vermiculite under different conditions

\begin{tabular}{|c|c|c|c|c|c|}
\hline Entry & Catalyst & Temperature & $\begin{array}{l}\text { Pressure } \\
\text { (Bars) }\end{array}$ & $\begin{array}{l}\text { PO } \\
\text { Conversion } \\
{[\%]}\end{array}$ & $\begin{array}{l}\text { PC } \\
\text { Selectivity } \\
{[\%]}\end{array}$ \\
\hline 1 & Talc & 100 & 20 & 59.3 & 94.4 \\
\hline 2 & Talc & 100 & 30 & 60.5 & 94.6 \\
\hline 3 & Talc & 120 & 30 & 68.7 & 94.2 \\
\hline 4 & Talc & 130 & 30 & 87.6 & 94.3 \\
\hline 5 & Talc & 140 & 10 & 97.5 & 93.6 \\
\hline 6 & Talc & 140 & 20 & 98.0 & 93.9 \\
\hline 7 & Talc & 140 & 30 & 98.9 & 93.7 \\
\hline 8 & Talc & 140 & 35 & 99.0 & 93.4 \\
\hline 9 & Talc & 150 & 30 & 99.3 & 92.2 \\
\hline 10 & $\begin{array}{l}\text { Vermicu- } \\
\text { lite }\end{array}$ & 140 & 30 & 90.1 & 95.3 \\
\hline 11 & $\begin{array}{l}\text { Vermicu- } \\
\text { lite }\end{array}$ & 150 & 30 & 92.6 & 93.7 \\
\hline $12^{\mathrm{a}}$ & Talc & 140 & 30 & 70.8 & 94.0 \\
\hline $13^{b}$ & Talc & 140 & 30 & 99.2 & 92.8 \\
\hline $14^{c}$ & Talc & 140 & 30 & 95.3 & 87.0 \\
\hline $15^{d}$ & Talc & 140 & 30 & 96.8 & 92.4 \\
\hline
\end{tabular}

Reaction conditions: propylene oxide $(10 \mathrm{mmol})$, catalyst $(100 \mathrm{mg})$, TBAB ( $2.5 \mathrm{~mol} \%$ of epoxide), $\mathrm{CO}_{2}$ (10-35 bars), $\mathrm{MeCN}(5 \mathrm{ml})$, Temperature (100$\left.150^{\circ} \mathrm{C}\right)$, Time $(20 \mathrm{~h})$

$P O$ propylene oxide, $P C$ propylene carbonate

a Time $12 \mathrm{~h}$

b Time $24 \mathrm{~h}$

c $\mathrm{CH}_{2} \mathrm{Cl}_{2}$ solvent

d DMF solvent

was used as co-catalyst, there was a reduction in both PO conversion and PC selectivity (Table 3, entry 12). This could be attributed to higher basicity of DMAP that might lead to formation of relatively stable intermediates hence affecting conversion and selectivity.

\section{Effect of reaction conditions}

The effect of different reaction conditions such as temperature, pressure, reaction time and solvent were studied in order to improve conversion and selectivity of the $\mathrm{CO}_{2}$ and epoxide coupling catalyzed by phyllosilicates and TBAB. Talc and vermiculite that had exhibited superior performance in the cycloaddition reaction compared to other phyllosilicates were selected for further study and the results are presented in Table 3.

Temperature and $\mathrm{CO}_{2}$ pressure had a significant effect on the PO conversion whereas the PC selectivity was not particularly sensitive to these reaction conditions. The optimum temperature for the cycloaddition reaction was $140{ }^{\circ} \mathrm{C}$ with a pressure of 30 bars giving an overall PC yield of 93\% (Table 2, entry 7). The effect of pressure on 
PO conversion was fairly small compared to the temperature effect and no improvement was seen above 30 bars. This observation is in agreement with earlier studies that reported no significant effect of pressure on the cycloaddition process in the range $30-100$ bars $[18,54]$. Furthermore, an increase in reaction time resulted into a higher conversion of PO, albeit with a slightly lower PC selectivity (Table 3, entry 7, 12 and 13). Results also showed that the effect of solvents was large with acetonitrile $(\mathrm{MeCN})$ and dimethylformamide (DMF) giving a high PC selectivity, whereas dichloromethane (DCM) suppressed selectivity. Similar solvent effects have been previously reported [20, 56-58].

\section{Effect of heat pre-treatment of the catalysts}

The effect of heat pre-treatment of the phyllosilicates on the catalytic activity was also studied and the results are presented in Table 4. Generally, the activity of the catalysts reduced slightly with an increase in calcination temperature (Table 4, entry 1 to 3 ), whereas the selectivity of the catalytic system slightly improved with heat pretreatment of the phyllosilicates.

Prolonged storage of the ground phyllosilicates had a negative effect on their catalytic performance (Table 4, entry 10). The catalytic activity of the phyllosilicate minerals is derived from chemical behavior of the surface functional groups [59]. When the phyllosilicate layers are disturbed, during grinding, a diversity of functional groups is exposed. Since these groups were in the interior of the crystal, they become coordinatively unsaturated

Table 4 Conversion and selectivity in the coupling of $\mathrm{CO}_{2}$ and $\mathrm{PO}$ to produce PC catalysed by phyllosilicates calcined at different temperatures

\begin{tabular}{lllll}
\hline Entry & Catalyst & $\begin{array}{l}\text { Calcination } \\
\text { Temperature }\end{array}$ & $\begin{array}{l}\text { PO } \\
\text { Conversion } \\
{[\%]}\end{array}$ & $\begin{array}{l}\text { PC } \\
\text { Selectivity } \\
{[\%]}\end{array}$ \\
\hline 1 & Talc & 100 & 98.9 & 93.7 \\
2 & Talc & 300 & 96.7 & 94.5 \\
3 & Talc & 500 & 95.3 & 94.2 \\
4 & Vermiculite & 100 & 90.1 & 95.3 \\
5 & Vermiculite & 300 & 89.4 & 96.1 \\
6 & Vermiculite & 500 & 87.6 & 96.4 \\
$7^{[\mathrm{a}]}$ & Talc & 100 & 97.5 & 92.5 \\
$8^{[\mathrm{a}]}$ & Vermiculite & 100 & 88.2 & 95.6 \\
$10^{[\mathrm{b}]}$ & Talc & 100 & 96.5 & 92.8 \\
\hline
\end{tabular}

Reaction conditions: propylene oxide (10 mmol), catalyst (100 mg), TBAB ( $2.5 \mathrm{~mol} \%$ of epoxide), $\mathrm{CO}_{2}$ (30 bars), $\mathrm{MeCN}(5 \mathrm{ml})$, Temperature $\left(140^{\circ} \mathrm{C}\right)$, Time $(20 \mathrm{~h})$

$P O$ propylene oxide, $P C$ propylene carbonate

a co-catalyst TBAI

b Talc catalyst dried at $100^{\circ} \mathrm{C}$ and stored in a vial for 3 months when exposed causing them to be very reactive [48]. However, when the active groups of the catalysts are exposed to the atmosphere for a long time, they adsorb moisture and other species which may affect their catalytic performance [60].

\section{Proposed mechanism for the cycloaddition of $\mathrm{CO}_{2}$ and $\mathrm{PO}$ using talc/ TBAB catalytic system}

Studies have shown that the most effective catalysts for the cycloaddition reaction contain Lewis-acid sites for epoxide activation and nucleophilic groups to promote ring-opening of the epoxide [61]. A simplified illustrated talc structure (Fig. 5), shows that each basal (001) layer is comprised of the $\left[\mathrm{MgO}_{6}\right]$ octahedral sheet, sandwiched between two $\left[\mathrm{SiO}_{4}\right]$ tetrahedral sheets through shared oxygen atoms $[27,62]$. Various transition metal cations, including $\mathrm{Fe}^{2+}, \mathrm{Fe}^{3+}, \mathrm{Ni}^{2+}, \mathrm{Ti}^{3+}$, can be introduced into the octahedral sheet, whereas s-block metal cations, such as $\mathrm{Na}^{+}, \mathrm{Ka}^{+}, \mathrm{Ca}^{2+}$ and $\mathrm{Mg}^{2+}$, can also be introduced into the interlayers $[27,62]$. Introduction of metals into the structure of talc implies that its catalytic properties are tunable. Based on the results obtained in the $\mathrm{CO}_{2}$ and epoxide cycloaddition reaction, and the structure of talc as illustrated in Fig. 5, we propose a hydrogen bond assisted mechanism for this process. Hydrogen bonding between the catalyst and epoxide is thought to be a key factor in promoting the cycloaddition reaction for this type of mechanism.

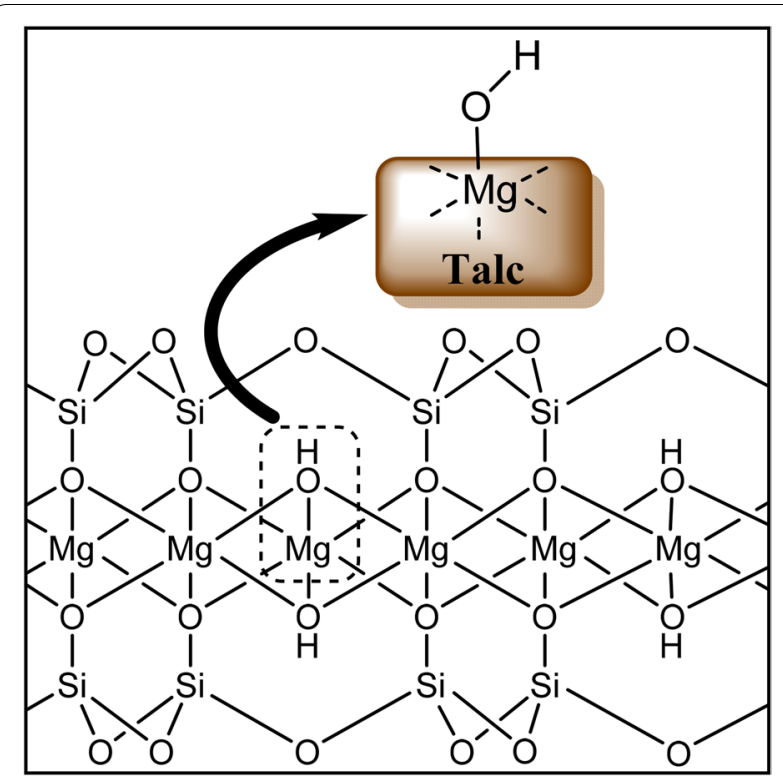

Fig. 5 Simplified illustrated structure of talc showing the $\left[\mathrm{MgO}_{6}\right]$ octahedral sheet sandwiched between two $\left[\mathrm{SiO}_{4}\right]$ tetrahedral sheets, through shared oxygen atoms 
In this work, talc or another phyllosilicate provides the Lewis-acid sites through the hydroxyl groups, while the co-catalyst (TBAB) provides the nucleophilic groups. As shown in Scheme 2, the hydroxyl group on the surface of talc acts as a weak acid, activating the epoxide by forming a hydrogen bond with it. The activated epoxide then undergoes a nucleophilic attack by $\mathrm{Br}$ - from the co-catalyst (TBAB), resulting in ring opening to form a halo-alkoxide. The oxygen anion of the ring-opened halo-alkoxide then interacts with $\mathrm{CO}_{2}$, which is activated by the Lewis acidic sites [63] to form an alkylcarbonate anion. The alkylcarbonate is transformed into a cyclic carbonate by intramolecular substitution of the $\mathrm{Br}$ - with the regeneration of TBAB. This mechanism is similar to that described for the cycloadditon of epoxides and $\mathrm{CO}_{2}$ using an iron-based composite catalyst rich in hydroxyl groups [22].
The results obtained using the heat pre-treated catalysts, further support the hydrogen bond assisted mechanism proposed for the $\mathrm{CO}_{2}$ and epoxide cycloaddition reaction. As shown in Table 4, an increase in calcination temperature in the range $100-500{ }^{\circ} \mathrm{C}$ resulted into a decrease in the activity of the catalysts (Table 4, entry $1-3)$. This might be considered contrary to what is expected since heating the phyllosilicates results in increased interlayer spacing which opens up the mineral structure. This would expose more potentially active sites resulting into enhanced catalytic activity, but in our study, a reduction in performance was observed. Thermal treatment of phyllosilicates in the temperature range $100-500^{\circ} \mathrm{C}$, does not cause significant structural or mineralogical decomposition of these minerals, but results in loss of water molecules $[64,65]$. The structural decomposition of talc commences at $~ 800{ }^{\circ} \mathrm{C}$, peaking at $~ 895{ }^{\circ} \mathrm{C}$, with the formation of enstatite and amorphous silica [64].
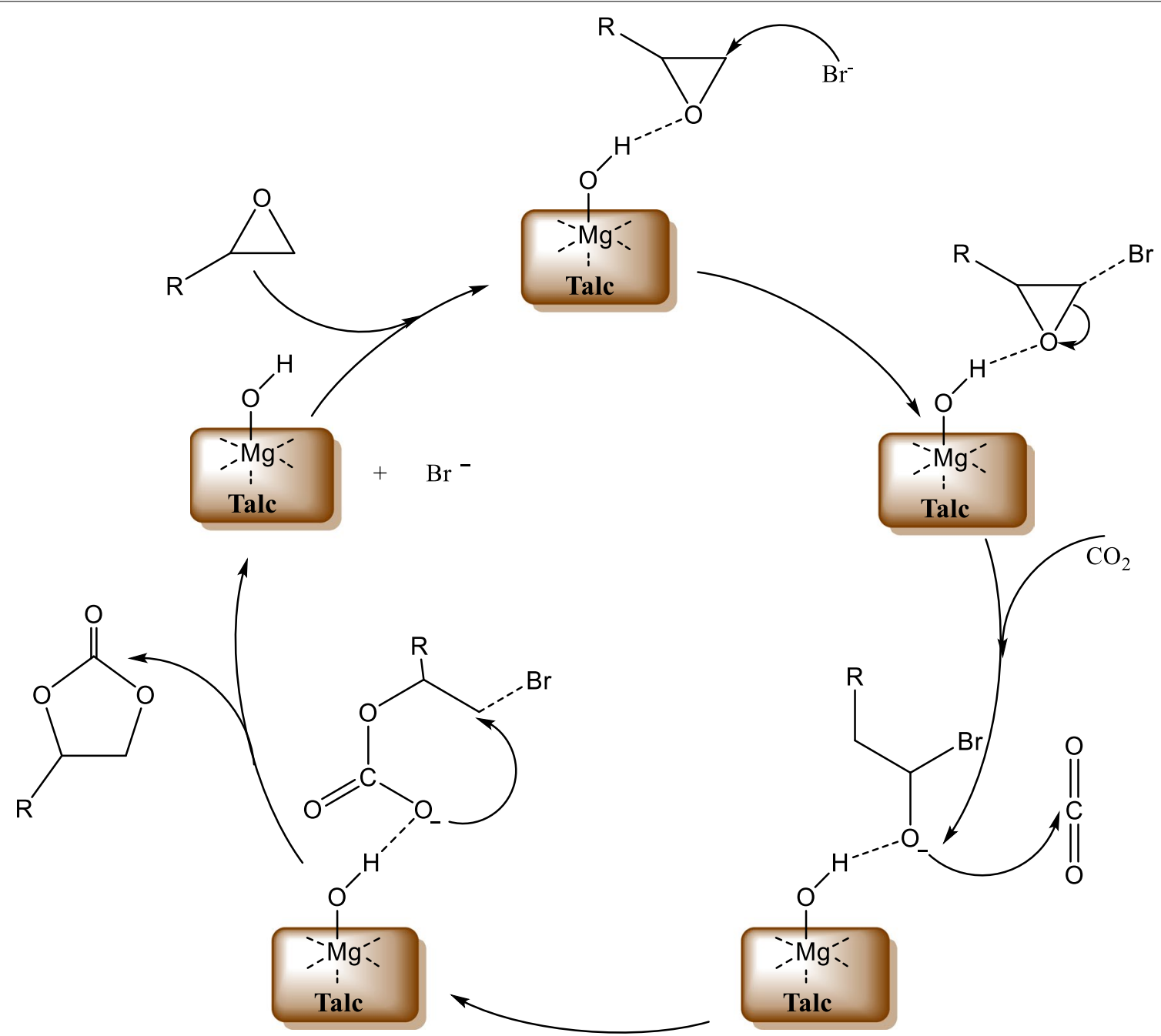

Scheme 2 Proposed mechanism for the hydrogen bond assisted cycloaddition of $\mathrm{CO}_{2}$ and epoxides catalyzed by Talc/TBAB 
Since the surface activity of the phyllosilicates is attributable to the presence of hydroxyl groups which coordinate and activate the epoxide through hydrogen bonding, loss of these groups as water molecules would result into a reduction in catalytic activity. These observations, provides more support for the proposed mechanism in Scheme 2, where the hydroxyl groups play a vital role in activating the epoxide.

Vermiculite also exhibited significant activity in the epoxide and carbon dioxide cycloaddition process, although its efficiency was slightly lower than that of talc. This is not surprising since vermiculite has some talclike layers and contains $\mathrm{Mg}^{2+}$ and $\mathrm{Al}^{3+}$ ions, which are potentially active sites in the cycloaddition reaction. The reduction in catalytic activity of vermiculite compared to talc, could be because some of the active sites in the former are obscured by composition water. Indeed, water molecules, especially weakly bonded non-solvating ones, could compete with reagents for adsorption sites and hamper activity.

\section{$\mathrm{CO}_{2}$ coupling with various epoxides catalyzed by talc/TBAB}

Basing on the interesting results obtained in the $\mathrm{CO}_{2}$ and $\mathrm{PO}$ coupling reaction using talc and TBAB under optimal conditions, different epoxides were also tested and the results are presented in Table 5. High conversion and selectivity to the corresponding cyclic carbonate was observed for epichlorohydrin, propylene oxide, butylene oxide and styrene oxide under the optimized reaction conditions (Table 5, entry $1-4$ ). All cyclic carbonates were produced in $\geq 90 \%$ yields with the exception of butylene carbonate which was obtained in a slightly lower yield of $86.5 \%$. The catalytic process could also be carried out with a reduced amount of the co-catalyst, although slightly lower cyclic carbonate yield was observed (Table 5, entry 7). After the catalytic runs, the phyllosilicate part of the catalyst system was recovered by filtration, washed, dried and re-used with a fresh amount of TBAB. The epoxide conversions and cyclic carbonate selectivities in the subsequent runs were similar to those obtained with fresh catalyst, suggesting that the catalyst could be used a number of times without significant loss in activity (Table 5, entry 5 and 6). The talc/ TBAB and vermiculite/TBAB catalyst systems in this study, exhibited good activity in the cycloaddition of $\mathrm{CO}_{2}$ with epoxides, producing the corresponding cyclic carbonates in high yields. Though some previous studies have reported medium to high yields of cyclic carbonates in the cycloaddition process utilizing comparable inorganic heterogeneous catalytic systems $[22,26,66]$, the performance of these catalysts was challenged under solvent free conditions.
Avoiding use of solvents in chemical processing is a key goal in green chemistry. To this end, the $\mathrm{CO}_{2}$ and epoxide cycloaddition reaction was also carried out in the absence of a solvent, and the results are shown in Table 5. High conversions of $\geq 90 \%$ were obtained for a number of epoxides without loss of selectivity to the corresponding cyclic carbonate (Table 5; entry 8 to 10 ). A few studies have reported use of inorganic heterogenous catalysts for the cyclic carbonate synthesis in the absence of solvent, although most of the systems had conversion and selectivity challenges. Yamaguchi and co-workers [18], employed several metal oxides for the coupling of $\mathrm{CO}_{2}$ and $\mathrm{PO}$ to form $\mathrm{PC}$ in the absence of a solvent. The best oxide, gave a yield of $32 \%$ at $150{ }^{\circ} \mathrm{C}$ and 80 bars of $\mathrm{CO}_{2}$. Fujita and co-workers [24], used smectite based catalysts containing various amounts of alkali metals in the cycloaddition of $\mathrm{CO}_{2}$ and $\mathrm{PO}$ without a solvent. The most active smectite catalyst gave a PC yield of $80 \%$ at $150{ }^{\circ} \mathrm{C}$ and 80 bars of $\mathrm{CO}_{2}$. Srivastava and co-workers [26], reported a PC yield of $86.3 \%$ when utilizing zeolite based organic-inorganic hybrid catalysts for the $\mathrm{CO}_{2}$ and epoxide coupling under solvent free conditions. The present catalyst system offers a PC yield of $87.4 \%$ in the absence of a solvent, which is slightly higher than the systems previously reported and mentioned above. Furthermore, the corresponding cyclic carbonates for other epoxides such as epichlorohydrin and styrene oxide were also produced in high yields under solvent-free conditions. Therefore, the results of this study, ably demonstrate the catalytic potential of talc and vermiculite in the cycloaddition of $\mathrm{CO}_{2}$ and epoxide to form cyclic carbonates in excellent yields, despite need for a co-catalyst. The low cost and availability of naturally occurring talc and other phyllosilicate deposits, makes this strategy attractive for the cycloaddition process.

\section{Conclusion}

We have successfully demonstrated the use of talc and other physllosilicates as tunable catalysts for the direct synthesis of cyclic carbonates from $\mathrm{CO}_{2}$ and epoxide. These naturally occurring materials show high activity in the $\mathrm{CO}_{2}$ and epoxide coupling reaction in the presence of $\mathrm{TBAB}$ as a co-catalyst producing the corresponding cyclic carbonates in excellent yields and selectivity. The phyllosilicate part of the catalysts is easily recovered by filtration and can be reused several times. The catalyst system can also work efficiently under solvent-free conditions. These naturally occurring minerals are low cost, stable and efficient catalysts for the cycloaddition process with potential for further exploration. 
Table 5 Conversion and selectivity in the coupling of various epoxides and $\mathrm{CO}_{2}$ catalysed by Talc dried at $100{ }^{\circ} \mathrm{C}$

\begin{tabular}{|c|c|c|c|c|}
\hline Entry & Epoxide & Cyclic carbonate & Time (h) & Yield*[\%] \\
\hline 1 & $\mathrm{O}$ & & 6 & 91.8 \\
\hline 2 & $\mathrm{O}$ & & 20 & 92.7 \\
\hline 3 & $\mathrm{O}$ & $\mathrm{O}$ & 12 & 86.6 \\
\hline 4 & $\mathrm{O}$ & & 12 & 91.5 \\
\hline $5^{[a]}$ & $\Omega$ & & 6 & 91.0 \\
\hline $6^{[b]}$ & O & & 6 & 90.6 \\
\hline $7^{[c]}$ & $\mathrm{O}$ & & 20 & 90.7 \\
\hline $8^{[d]}$ & $\mathrm{O}$ & & 6 & 88.5 \\
\hline$g^{[d]}$ & $\mathrm{O}$ & & 20 & 87.4 \\
\hline $10^{[d]}$ & & & 12 & 90.1 \\
\hline
\end{tabular}

Reaction conditions:epoxide $(10 \mathrm{mmol})$, Talc $(100 \mathrm{mg}), \operatorname{TBAB}\left(2.5 \mathrm{~mole} \%\right.$ of epoxide), $\mathrm{CO}_{2}(30 \mathrm{bars}), \mathrm{MeCN}(5 \mathrm{ml})$, Temperature $\left(140^{\circ} \mathrm{C}\right)$ Yield $^{*}=$ conversion $\mathrm{x}$ selectivity

${ }^{a}$ recycled catalyst

${ }^{\mathrm{b}}$ twice recyled catalyst

c TBAB (2 mole\% of epoxide). ${ }^{d}$ no solvent, epoxide $(20 \mathrm{mmol})$, Talc $(200 \mathrm{mg})$, TBAB (2.5 mole\% of epoxide) 


\section{Experimental section}

\section{General considerations}

Commercially available solvents and reagents were used as received. The natural vermiculite samples were obtained from Namekhara mines, Manafwa District, Eastern Uganda. The natural talc samples were obtained from Lolung-Moruamakale deposits in Moroto District, Northern Uganda. Other phyllosilicates, were selected from voucher mineral samples at the Department of Geology and Petroleum studies, College of Natural Sciences, Makerere University. The elemental composition of the samples was determined using ICP on a PerkinElmer OPTIMA 3000 DV Instrument. The IR spectra of the catalysts were recorded on a Shimadzu FTIR 8201 $\mathrm{PC}$ instrument using $\mathrm{KBr}$ discs. Gas chromatography analyses were done with a Hewlett Packard 5890 Series II gas chromatograph equipped with an FID detector. GC-MS studies were performed on an Agilent $6890 \mathrm{~N}$ instrument. The surface area, average adsorption pore size and volume for the talc catalysts were measured by Nitrogen gas analysis using a Micromeritics ASAP 2420 instrument.

\section{Catalyst preparation and pretreatment}

Naturally occurring phyllosilicates including talc, vermiculite, chlorite, phlogopite and biotite were selected for the study. The samples were dried at $100{ }^{\circ} \mathrm{C}$, crushed in a mortar, and the resultant catalyst powder stored in tightly closed sample bottles. Some of the samples were calcined at different temperature in the range $300-500{ }^{\circ} \mathrm{C}$ before being tested in the cycloaddition process. Talc and vermiculite showed the most promising results in catalysis and were fully characterized using different techniques whereas the other phyllosilicates were used without any further characterization. Muscovite was not included in the study because of its sheet like nature.

\section{Powder X-ray diffraction}

$\mathrm{X}$-ray powder diffraction data for the mineral samples was collected in transmission mode using a Stoe Stadi MP diffractometer $(\mathrm{Cu} \mathrm{K} \alpha 1, \lambda=1.54051 \AA$, detector Mythen $1 \mathrm{~K}$, step size $0.015^{\circ}$ ). Samples of pristine minerals were gently crushed in mortar to small particles of $\sim 0.1-0.2 \mathrm{~mm}$ size but without excessive comminution, in order to avoid extensive structure distortion. The talc powder was put between two sticky layers of scotch in a flat sample holder for the measurement in $\theta-2 \theta$ mode ( 4 runs were merged, $2 \theta=2-116^{\circ}, 5^{\circ}$ PSD step, $40 \mathrm{~s} /$ PSD step). The powder of vermiculite, consisting of thin platelets, was measured in a rotating glass capillary with diameter $0.3 \mathrm{~mm}$ ( 5 runs were merged, $2 \theta=2-121^{\circ}$, $5^{\circ}$ PSD step, $420 \mathrm{~s} / \mathrm{PSD}$ step) in Debye-Scherrer mode. The phase composition of samples was determined by comparison of the powder diffraction data with powder patterns of known phases using the program package Stoe WinXPOW [37, 45, 49].

\section{Catalytic reactions}

The $\mathrm{CO}_{2}$ and epoxide cycloaddition reactions were performed in a $100 \mathrm{~mL}$ stainless steel autoclave equipped with a magnetic stirrer. The epoxide $(10-20 \mathrm{mmol})$, catalyst (0-200 mg), co-catalyst (0-2.5 mol \% of epoxide) and solvent $(0-5 \mathrm{ml})$ were loaded into the autoclave. The autoclave was purged with $\mathrm{CO}_{2}$ and then pressurized with an appropriate amount of $\mathrm{CO}_{2}$ (10-35 bar). The reaction was carried out at the desired temperature $\left(100-150{ }^{\circ} \mathrm{C}\right)$ for a duration of $4-24 \mathrm{~h}$ with constant stirring. At the end of the reaction, the reactor was cooled in an ice-water bath, and the unreacted $\mathrm{CO}_{2}$ released slowly. All catalytic runs were performed in duplicates and the average result evaluated. The products were analysed using a combination of GC-FID and $\mathrm{GC}-\mathrm{MS}$ with reference to an internal standard (biphenyl) which was added to the mixture before the reaction. Where necessary, the cyclic carbonates were obtained from the reaction mixture using distillation or recrystallization from ethanol [67].

\section{Supplementary information}

Supplementary information accompanies this paper at https://doi. org/10.1186/s13065-020-00713-2.

Additional file 1: Figure S1. FTIR Spectrum of talc. Figure S2. $\mathrm{N}_{2}$ Adsorption-desorption isotherm.

\section{Abbreviations}

CAS: Centre for Analysis and Synthesis; $\mathrm{CO}_{2}$ : Carbon dioxide; DCM: Dichloromethane; DMAP: N, N-dimethylamino pyridine; DMF: Dimethylformamide; FID: Flame ionization detector; GC: Gas chromatography; IPICS: International Programme in Chemical Sciences; ISP: International Science Programme; MS: Mass spectrometry; OPCW: Organization for Prohibition of Chemical Weapons; PC: Propylene carbonate; PO: Propylene oxide; PXRD: Powder X-ray diffraction; QAS: Quarternary ammonium salts; TBAB: N-tetra butyl ammonium bromide; TBAI: N-tetra butyl ammonium iodide.

\section{Acknowledgements}

The Authors thank the Department of Geology and Petroleum studies, College of Natural Sciences, Makerere University, for providing some of the pristine minerals used in the study. We also thank Lund University, Sweden, for providing key instruments used in the study.

\section{Authors' contributions}

FN, OFW and ET participated in experimental design and coordination of laboratory activities. FN, IO and ET performed sample preparation, sample analysis and catalytic runs. FN, SAN, IO, OFW and ET participated in data analysis and write-up of the manuscript. All authors read and approved the final manuscript.

\section{Funding}

The work was financially supported by the International Programme in Chemical Sciences (IPICS), under the International Science Programme (ISP), Uppsala University, Sweden. FN received a fellowship to CAS, from the Organization for 
Prohibition of Chemical Weapons (OPCW). IO received a Scholarship to CAS, from the Swedish Institute under the Visby program.

\section{Availability of data and materials}

All supporting information including figures and detailed methods is available upon request.

\section{Ethics approval and consent to participate}

Not applicable.

\section{Consent for publication}

Not applicable.

\section{Competing interests}

The authors declare that they have no competing interests.

\section{Author details}

${ }^{1}$ Department of Chemistry, College of Natural Sciences, Makerere University, P. O. Box 7062, Kampala, Uganda. ${ }^{2}$ Centre for Analysis and Synthesis, Department of Chemistry, Lund University, P.O. Box 124, 22100 Lund, Sweden.

${ }^{3}$ Department of Inorganic Chemistry, Ivan Franko National University of Lviv, Kyryla i Mefodiya Str. 6, Lviv 79005, Ukraine.

Received: 11 June 2020 Accepted: 6 October 2020

Published online: 20 October 2020

\section{References}

1. Aresta M (2003) Carbon dioxide recovery and utilization. Springer Netherlands Publishers, Berlin

2. Shafiee S, Topal E (2009) When will fossil fuel reserves be diminished? Energy Policy 37:181-189

3. Höök M, Tang X (2013) Depletion of fossil fuels and anthropogenic climate change - a review. Energy Policy 52:797-809

4. Halmann MM, Steinberg M (2001) Greenhouse gas carbon dioxide mitigation: science and technology. J Am Chem Soc 123(29):7197-7197

5. Nel W P, Cooper C J (2009) Implications of Fossil Fuel Constrains on Economic Growth and Global Warming. Energy Policy 166-180.

6. Mikkelsen M, Jørgensen M, Kerbs FC (2010) The teraton challenge. a review of fixation and transformation of carbon dioxide. Energy Environ Sci 3:43-81

7. Yuan G, Qi C, Wu W, Jiang H (2017) Recent advances in organic synthesis with $\mathrm{CO}_{2}$ as $\mathrm{C} 1$ synthon. CurrOpin Green Sustain Chem 3:22-27

8. Aresta M, Dibenedetto A (2004) The contribution of the utilization option to reducing the $\mathrm{CO}_{2}$ atmospheric loading: research needed to overcome existing barriers for a full exploitation of the potential of the $\mathrm{CO}_{2}$ use. Catal Today 98(4):455-462

9. Aresta M, Dibenedetto A (2007) Utilisation of carbon dioxide as a chemical feedstock: opportunities and challenges. Dalton Transact 28:2975-2992

10 Meylan FD, Moreau V, Erkman S (2015) $\mathrm{CO}_{2}$ utilization in the perspective of industrial ecology, an overview. J $\mathrm{CO}_{2}$ Util 12:101-108

11. Markewitz P, Kuckshinrichs W, Leitner W, Linssen J, Zapp P, Bongartz R, Schreiber A, Müller TE (2012) Worldwide innovations in the development of carbon capture technologies and utilization of $\mathrm{CO}_{2}$. Energy Envron Sci 5:7281-7305

12. Shaikh AAG, Sivaram S (1996) Organic carbonates. Chem Rev 96(3):951-976

13. Schäffner B, Schäffner F, Verevkin SP, Börner A (2010) Organic Carbonates As Solvents In Synthesis And Catalysis. Chem Rev 110:4554-4581

14. Balaraman E, Gunanathan C, Zhang J, Shimon LJW, Milstein D (2011) Efficient hydrogenation of organic carbonates, carbamates and formates indicates alternative routes to methanol based on $\mathrm{CO}_{2}$ and $\mathrm{CO}$. Nat Chem 3:609-614

15. Clements HJ (2003) Reactive applications of cyclic alkylene carbonates. Ind Eng Chem Res 42(4):663-674

16. Lu XB, Darensbourg DJ (2012) Cobalt catalysts for the coupling of $\mathrm{CO}_{2}$ and epoxides to provide polycarbonates and cyclic carbonates. Chem Soc Rev 41:1462-1484
17. Yoshida M, Ihara M (2004) Novel methodologies for the synthesis of cyclic carbonates. Chemistry 10(12):2887-2893

18. Yamaguchi K, Ebitani K, Yoshida T, Yoshida H, Kaneda K (1999) Mg-Al mixed oxides as highly active acid-base catalysts for cycloaddition of carbon dioxide to epoxides. J Am Chem Soc 121(18):4526-4527

19. Bhanage BM, Fujita S, Ikushima Y, Arai M (2001) Synthesis of dimethyl carbonate and glycols from carbon dioxide, epoxides, and methanol using heterogeneous basic metal oxide catalysts with high activity and selectivity. Appl Catal A 219(1-2):259-266

20. Yano T, Matsui H, Koike T, Ishiguro H, Fujihara H, Yoshihara M, Maeshima $\mathrm{T}$ (1997) Magnesium oxide-catalysed reaction of carbon dioxide with an epoxide with retention of stereochemistry. Chem Commun $12: 1129-1130$

21. Tu M, Davis RJ (2001) Cycloaddition of $\mathrm{CO}_{2}$ to epoxides over solid base catalysts. J Catal 199(1):85-91

22. Qu J, Cao C, Dou Z, Liu H, Yu Y, Li P, Song W (2012) Synthesis of cyclic carbonates: catalysis by an iron-based composite and the role of hydrogen bonding at the solid / liquid interface. ChemSusChem 5:652-655

23. Bhanage BM, Fujita S, Ikushima Y, Toriib K, Arai M (2003) Synthesis of dimethyl carbonate and glycols from carbon dioxide, epoxides and methanol using heterogeneous Mg containing smectite catalysts: effect of reaction variables on activity and selectivity performance. Green Chem 5:71-75

24. Fujita S, Bhanage BM, Ikushima Y, Shirai M, Torii K (2002) Chemical fixation of carbon dioxide to propylene carbonate using smectite catalysts with high activity and selectivity. Catal Lett 79:95-98

25. Li CG, Xu L, Wu P, Wu H, He M (2014) efficient cycloaddition of epoxides and carbon dioxide over novel organic-inorganic hybrid zeolite catalysts. ChemCommun 50:15764-15767

26. Srivastava R, Srinivas D, Ratnasamy P (2005) Zeolite-based organicinorganic hybrid catalysts for phosgene-free and solvent-free synthesis of cyclic carbonates and carbamates at mild conditions utilizing $\mathrm{CO}_{2}$. Appl Catal A 289(2):128-134

27. Hurlbut SC (1971) The manual of mineralogy, 19th edn. John Wiley \& Sons, New York

28. Narayan S, Muldoon J, Finn MG, Fokin W, Kolb HC, Sharpless KB (2005) On water: unique reactivity of organic compounds in aqueous suspension. Angew Chem Int Ed 44:3275-3279

29. Niu F, Liu CC, Cui ZM, Zhai J, Jiang L, Song WG (2008) Promotion of organic reactions by interfacial hydrogen bonds on hydroxyl group rich nano-solids. ChemCommun 39:2803-2805

30. Niu F, Zhang L, Luo SZ, Song WG (2010) Room temperature aldol reactions using magnetic $\mathrm{Fe}_{3} \mathrm{O}_{4} @ \mathrm{Fe}(\mathrm{OH})_{3}$ composite microspheres in hydrogen bond catalysis. Chem Commun 46:1109-1111

31. Tajbakhsh M, Heydari A, Khalilzadeh MA, Lakouraj MM, Zamenian B, Khaksar S (2007) Amberlyst-15 as a heterogeneous reusable catalyst for the synthesis of a-hydroxy phosphonates in water. Synlett 15:2347-2350

32. Sun J, Ren JY, Zhang SJ, Cheng WG (2009) Water as an efficient medium for the synthesis of cyclic carbonate. Tetrahedron Lett 50:423-426

33 Takahashi T, Watahiki T, Kitazume S, Yasuda H, Sakakura T (2006) Synergistic hybrid catalyst fpr cyclic carbonate synthesis: Remarkable acceleration caused by immobilization of homogeneous catalyst on silica. Chem Commun 37:1664-1666

34. Khalilzadeh MA, Hosseini A, Shokrollahzadeh M, Halvagar MR, Ahmadi D, Mohannazadeh F, Tajbakhsh $\mathrm{M}(2006) \mathrm{HIO}_{4} / \mathrm{Al}_{2} \mathrm{O}_{3}$ as a new system for iodination of activated aromatics and 1,3-dicarbonyl compounds. Tetrahedron Lett 47:3525-3528

35. Li C, Wan R, Lu X, Zhang M (2013) Mineralogical characteristics of unusual black talc ores in Guangfeng County, Jiangxi Province, China. Appl Clay Sci 74:37-46

36. Nkoumbou C, Villieras F, Njopwouo D, Yonta C, Barres NO, Pelletier M, Razafitianamaharavo A, Yvon J (2008) Physicochemical properties of talc ore from three deposits of Lamal Pougue area (Yaounde Pan-African Belt, Cameroon) in relation to industrial uses. Appl Clay Sci 41:113-132

37. Argüelles A, Leoni M, Blanco JA, Marcos C (2010) Semi-ordered crystalline structure of the Santa Olalla vermiculite inferred from X-ray powder diffraction. Am Mineral 95:126-134

38. Mathieson AM, Walker GF (1954) Crystal structure of magnesium-vermiculite. Am Mineral 39(3-4):231-255 
39. Petit S, Martin F, Wiewiora A, De Parseval P, Decarreau A (2004) Crystalchemistry of talc: a near infrared (NIR) spectroscopy study. Am Mineral 89(2-3):319-326

40 Farmer VC (1974) The Layer silicates. In: Farmer VC (ed) The infrared spectra of minerals. Mineralogical Society, London, pp 331-363

41. Čavajda V, Uhlík P, Derkowski A, Čaplovičová M, Madejová J, Mikula M, Ifka $T$ (2015) Influence of grinding and sonication on the crystal structure of talc. Clays Clay Miner 63(4):311-327

42. Ersoy B, Dikmen S, Yildiz A, Gören R, Elitok Ö (2013) Mineralogical and physicochemical properties of talc from Emirdağ, Afyonkarahisar, Turkey. Turk J Earth Sci 22:632-644

43. Anovitz LM, Cole DR (2015) Characterization and analysis of porosity and pore structures. Rev Mineral and Geochem 80:61-164

44. Sprynskyy M, Kowalkowski T, Tutu H, Cukrowska E (2011) Adsorption performance of talc for uranium removal from aqueous solution. Chem Eng J 171(3):1185-1193

45. Perdikatsis B, Burzlaff H (1981) Strukturverfeinerung am Talk $\mathrm{Mg}_{3}\left[(\mathrm{OH})_{2} \mathrm{Si}_{4} \mathrm{O}_{10} \cdot\right.$ Z Kristallogr 156(3-4):177-186

46. Kumar SH, Singh KJ, Somani AK (2016) Estimatation of talc properties after milling. Am Inst Phys Conf Proc 17228:20139

47. Kogure T, Kameda J, Matsui T, Miyawaki R (2006) Stacking structure in disordered talc: Interpretation of its X-ray diffraction pattern by using pattern simulation and high-resolution transmission electron microscopy. Am Mineral 91:1363-1370

48. Wills BA (1997) Mineral Processing Technology, 6th edn. Butterworth Heinmann, Cornwall

49. Shirozu H, Bailey SW (1966) Crystal structure of a two-layer Mg-vermiculite. Am Mineral 51(7):1124-1143

50. Balou J, Khalilzadeh MA, Zareyee D (2019) An efficient and reusable nano catalyst for the synthesis of benzoxanthene and chromene derivatives. Sci Rep 9:3605

51. Whiteoak CJ, Martin E, Belmonte MM, Benet-Buchholz J, Kleij AW (2012) An efficient iron catalyst for the synthesis of five- and sixmembered organic carbonates under mild conditions. Adv SynCatal 354(2-3):469-476

52. Wang $X$, Wang $L$, Zhao $Y$, Kodama $K$, Hirose $T$ (2017) Efficient and practical organocatalytic system for the synthesis of cyclic carbonates from carbon dioxide and epoxides: 3-hydroxypyridine / tetra-n-butylammonium iodide. Tetrahedron 73:1190-1195

53. Fukuoka S, Kawamura M, Komiya K, Tojo M, Hachiya H, Hasegawa K, Aminata M, Okamoto H, Fukawa I, Komo S (2003) A novel non-phosgene polycarbonate production process using by-product $\mathrm{CO}_{2}$ as starting material. Green Chem 5:497-507

54. Wang JQ, Kong DL, Chen JY, Cai F, He LN (2006) Synthesis of cyclic carbonates from epoxides and carbon dioxide over silica-supported quaternary ammonium salts under supercritical conditions. J Mol Catal A Chem 249:143-148

55. Caló V, Nacci A, Monopoli A, Fanizzi A (2002) Cyclic carbonate formation from carbon dioxide and oxiranes in tetrabutylammonium halides as solvents and catalysts. Org Lett 4(15):2561-2563
56. Yasuda H, He LN, Sakakura T (2002) Cyclic carbonate synthesis from supercritical carbon dioxide and epoxide over lanthanide oxychloride. J Catal 209:547-550

57. Aresta M, Dibenedetto A, Gianfrate L, Pastore C (2003) Nb(V) compounds as epoxides carboxylation catalysts: the role of the solvent. J Mol Catal A Chem 204-205:245-252

58. Mori K, Mitani Y, Hara T, Mizugaki T, Ebitani K, Kaneda K (2005) A singlesite hydroxyapatite-bound zinc catalyst for highly efficient chemical fixation of carbon dioxide with epoxides. ChemCommun 36:3331-3333

59. Sposito G (1984) The surface chemistry of soils. Oxford University Press, Oxford

60. Yariv S (1992) The effect of tetrahedral substitution of Si by Al on the surface acidity of the oxygen plane of clay minerals. Int Rev Phys Chem 11(2):345-375

61. North M, Pasquale R, Young C (2010) Synthesis of cyclic carbonates from epoxides and $\mathrm{CO}_{2}$. Green Chem 12:1514-1539

62. Gaines RV, Skinner HC, Foord EE, Mason B, Rosenzweig A (1997) Dana's new mineralogy: the system of mineralogy of James Dwight Dana and Edward Salisbury Dana, 8th edn. John Wiley \& Sons, New York, pp $1437-1442$

63. Heimann JE, Bernskoetter WH, Hazari N (2019) Understanding the individual and combined effects of solvent and lewis acid on $\mathrm{CO}_{2}$ insertion into a metal hydride. J Am Chem Soc 141:10520-10529

64. Liu X, Liu X, Hu Y (2014) Investigation of the thermal decomposition of talc. Clays Clay Miner 62(2):137-144

65. Balek V, Šubrt J, Pérez-Maqueda LA, Beneš M, Bountseva IM, Beckman IN, Pérez-Rodríguez JL (2008) Thermal behavior of ground talc mineral. J Min Metall B 7:7-17

66. Lin YF, Huang KW, Ko BT, Lin KYA (2017) Bifunctional ZIF-78 heterogeneous catalyst with dual Lewis acidic and basic sites for carbon dioxide fixation via cyclic carbonate synthesis. J $\mathrm{CO}_{2}$ Util 22:178-183

67. Barkakaty B, Morino K, Sudoa A, Endo T (2010) Amidine-mediated delivery of $\mathrm{CO}_{2}$ from gas phase to reaction system for highly efficient synthesis of cyclic carbonates from epoxides. Green Chem 12:42-44

\section{Publisher's Note}

Springer Nature remains neutral with regard to jurisdictional claims in published maps and institutional affiliations.
Ready to submit your research? Choose BMC and benefit from:

- fast, convenient online submission

- thorough peer review by experienced researchers in your field

- rapid publication on acceptance

- support for research data, including large and complex data types

- gold Open Access which fosters wider collaboration and increased citations

- maximum visibility for your research: over $100 \mathrm{M}$ website views per year

At $\mathrm{BMC}$, research is always in progress.

Learn more biomedcentral.com/submissions 